\title{
Antimicrobial finishing of textiles for protection
}

Swapna Choudhury, Ava Rani Phukan and Pradip Kumar Borah

Received: 04.12.2017; Revised: 19.04.2018; Accepted: 07.05.2018

See end of the paper for authors' affiliations Swapna Choudhury Department of Textiles and Apparel Designing, College of Home Science, Assam Agricultural University, Jorhat (Assam) India Email : spatgirichoudhury@gmail. com
ABSTRACT : The antibacterial materials such as fabrics, clothes are becoming important to avoid cross infection by pathogenic micro-organisms, especially bacteria such as Aureimonas altamirensis, Bacillus clausii and Micrococcus yunnanensis, to control the infestation by microbes, and to arrest metabolism in microbes in order to reduce the formation of odour. Textiles for medical and hygienic use have become important areas in the textile industry. Therefore, to reduce/prevent infections, various antibacterial compounds have been used for all types of textiles. The solutions of disinfectant used are generally active in vitro, but, it is also necessary to know the effectiveness of disinfecting cloths in conditions of use. In the current study, it was aimed to determine the antibacterial activity of fabrics functionalized with herbal extracts against Aureimonas altamirensis, Bacillus clausii and Micrococcus yunnanensis, and also after different wash cycles against these bacteria. The results of the present study showed that the most susceptible bacterium was $B$. clausii in all standard test methods for unwashed fabrics, antibacterial activity was continued even after washing cycles.

KEY WORDS: Antibacterial activity, Aureimonas altamirensis, Bacillus clausii, Herbal extract, Micrococcus yunnanensis, Textile fabrics

- HOW TO CITE THIS PAPER : Choudhury, Swapna, Phukan, Ava Rani and Borah, Pradip Kumar (2018). Antimicrobial finishing of textiles for protection. Asian J. Home Sci., 13 (1) : 312-320, DOI: 10.15740/HAS/AJHS/13.1/312-320. Copyright@ 2018: Hind Agri-Horticultural Society. 